\title{
A Differential Viscosity Detector for Use in Miniaturized Chemical Separation Systems
}

\author{
Marko T. Blom, Emil Chmela, Frank H. J van der Heyden, R. Edwin Oosterbroek, Robert Tijssen, Miko Elwenspoek, \\ and Albert van den Berg
}

\begin{abstract}
In this paper, we present a micromachined differential viscosity detector suitable for integration into an on-chip hydrodynamic chromatography system. The general design, however, is applicable to any liquid chromatography system that is used for separation of polymers. The micromachined part of the detector consists of a fluidic Wheatstone bridge and a low hydraulic capacitance pressure sensor of which the pressure sensing is based on optical detection of a membrane deflection. The stand-alone sensor shows a resolution in specific viscosity of $3 \times 10^{-3}$, in which specific viscosity is defined as the increase in viscosity by a sample, relative to the baseline viscosity of a solvent.

[0947]
\end{abstract}

Index Terms-Microfluidics, viscometer, viscosity detection.

\section{INTRODUCTION}

\section{A. Liquid Chromatography}

$\mathbf{L}$ IQUID chromatography (LC) [1] is a powerful analysis technique, which can among others, be used for the analysis of polymers, aimed at the determination of the number of molecules of a certain mass. This provides the so-called Molecular Mass Distribution of the sample. The analysis is based on the separation of molecules of different sizes, and thus different masses, and subsequent detection. Separation is achieved by size-dependent interaction of the sample with a stationary phase in a separation channel. At the entrance of the separation channel a sample plug containing different polymer masses is defined. When this plug is moved through the channel, different masses will have different velocities and will thus elute from the channel at different times, which can be detected. Several techniques are available for detection of the plug after the separation is complete. Refractive index detection, ultraviolet (UV) absorption, fluorescence and viscometric detection are among the most common ones. Of those detection possibilities refractive index and viscometric detection are in principle applicable to all kinds of polymers.

Manuscript received October 21, 2002; revised February 20, 2004. This work was supported by the Dutch Technology Foundation STW. Subject Editor A. J. Ricco.

M. T. Blom was with the MESA+ Research Institute, University of Twente, The Netherlands, 7500 AE Enschede, The Netherlands. He is now with Micronit Microfluidics BV, Hengelosestraat 705, 7521 PA Enschede, The Netherlands (e-mail: marko.blom@micronit.nl).

E. Chmela and R. Tijssen are with the Department of Chemical Engineering, University of Amsterdam, The Netherlands.

F. H. J. van der Heyden is with the Department of Nanoscience, Delft University of Technology, The Netherlands.

R. E. Oosterbroek, M. Elwenspoek, and A. van den Berg are with the MESA+ Research Institute, University of Twente, The Netherlands, 7500 AE Enschede, The Netherlands.

Digital Object Identifier 10.1109/JMEMS.2004.840452

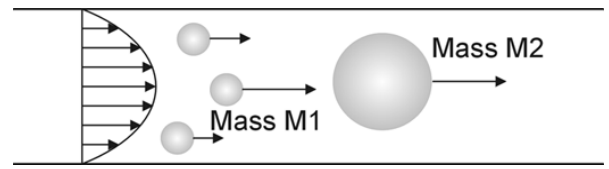

Fig. 1. The principle of hydrodynamic chromatography.

\section{B. Viscometric Detection}

Viscometric detection is based on the fact that a polymer plug in solution has a slightly higher viscosity than the solvent itself. Accordingly, the viscosity $\eta$ of a dilute polymer solution consists of a constant solvent viscosity $\eta_{0}$ and a specific viscosity $\eta_{s p}$ resulting from the polymers in solution [2]

$$
\eta=\eta_{0}\left(1+\eta_{s p}\right)=\eta_{0}(1+c[\eta]) .
$$

All variables used in this paper have been summarized in Table IV. The specific viscosity, which determines the required sensitivity of the viscosity detector, is proportional to the polymer concentration $c$ and the intrinsic viscosity $[\eta]$. The intrinsic viscosity is related to the polymer mass $M$ through the Mark-Houwink (2):

$$
[\eta]=k M^{a} .
$$

In this equation $k$ and $a(k, a>0)$ are empirically determined constants that give information about the polymer structure, for example long chain branching. Typical values for polystyrene in toluene are $k=17 \times 10^{-9} \mathrm{ml} / \mu \mathrm{g}$ and $a=0.69$ [3].

As can be seen from (1) and (2), viscometric detection is sensitive to both polymer concentration and mass. As such it can give additional information compared to detectors that are only sensitive to concentration, such as refractive index or absorption detectors.

Commercially available differential viscosity detectors have a resolution in specific viscosity of $10^{-5}$. For this proof-of-principle device we aim at a resolution of $10^{-4}$.

\section{Integration With On-Chip Hydrodynamic Chromatography}

The requirements of the detector design are related to the type of on-chip separation system the detector has to be coupled to. In this case we aim at integration with an on-chip Hydrodynamic Chromatography system as described in [4]-[6]. Separation by hydrodynamic chromatography is entirely based on the flow profile: in a small channel with a pressure-driven parabolic flow, larger molecules will not be able to approach the wall as much as smaller molecules and thus will have a larger average velocity (see Fig. 1). 


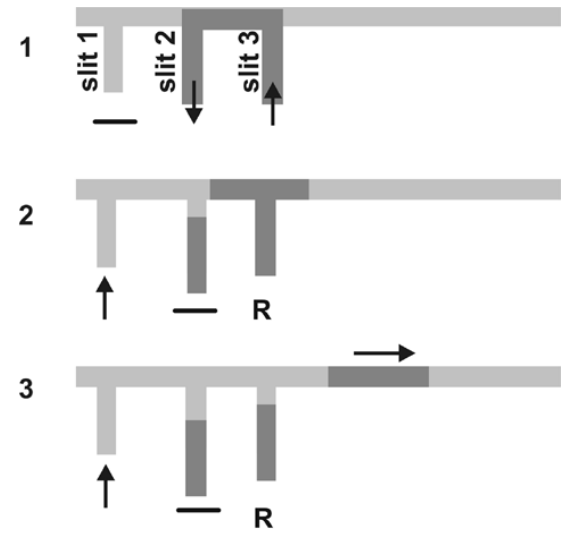

Fig. 2. Injection schematic. An explanation is given in the text.

In [7]-[9] it was shown that this principle could be used for chromatographic separations in fused silica capillaries with inner diameters in the micrometer range. Unfortunately, detection suffered from the low signal levels generated in the small detection volume. By using a planar chip configuration as described in [4]-[6] with a depth in the micrometer range and a channel that is as wide as possible, the detection volume can be increased while maintaining the geometrical separation. For practical reasons described in [4] the width is restricted to $1 \mathrm{~mm}$. Combined with a flow speed regime of $0.01-1 \mathrm{~mm} / \mathrm{s}$ this means that the volume flow is extremely low which is an important characteristic when designing the detector.

In order to be able to inject sub-nanoliter sample plugs into the separation channel, an injection structure was developed, which is shown in Fig. 2 [4], [10]. The three injection slits depicted in Fig. 2 are shown in a cross-section along the channel. In the first step sample is introduced between slit 2 and slit 3. In the second and third step slit 2 is closed and solvent is pushed through slit 1 moving part of the sample into the separation channel. The remaining part is pushed through a well-defined resistance connected to slit 3 in order to prevent tailing of the sample plug.

Furthermore polymer chromatography in general demands avoiding excessive shear stresses since so-called "shear-thinning" effects can influence the viscosity measurement [10]. This means in the presented design, employing channel heights in the micrometer range, that the linear velocity in the complete device cannot exceed $0.5 \mathrm{~mm} / \mathrm{s}$.

\section{INTEGRATED Viscosity DETECTION}

\section{A. Viscosity Detection Principles}

Several viscosity detection principles exist that are suitable for microtechnology fabrication. First of all, the fluidic resistance of a channel depends on the viscosity. Thus by measuring the pressure drop along a channel, the viscosity can be monitored [12], [13]. Secondly, the shear stress on a channel wall is a measure for the viscosity of the fluid moving along that wall. Several micromachined devices have been presented that are capable of measuring the shear stress [14]-[21]. Furthermore viscosity sensors have been described that use shear acoustic waves sensitive to viscosity and/or density changes [22]-[27].

In [28], [29] a microfabricated viscosity sensor is used that is capable of measuring a viscosity ratio between a sample and a reference stream combined in one channel. The sensing is based on the observation that the position of the dividing line depends on the flow and the viscosity ratio of the streams. This however only works on compounds that can be visualized. Moreover, optical detection is difficult if small volume flows are used as is necessary for coupling to a HDC chip.

All but the last of these techniques have the important disadvantage that they measure an absolute viscosity. Since for viscosity detection in polymer chromatography only a small change in viscosity on a large baseline must be detected the sensitivity of these techniques will not be sufficient. Accordingly a differential technique is required.

In [30], [31] a Wheatstone bridge configuration is used as shown in Fig. 3. Four equal fluidic resistances are arranged in a bridge. Initially the bridge is balanced and the differential pressure $\Delta P$ equals zero. A polymer peak entering the bridge changes the resistance value of the fluidic resistances in the lower branch and of the first resistance in the upper branch. As the peak is delayed in a large reservoir volume located before the last resistance in the upper branch, this resistance is not changed. The corresponding change in the differential pressure $\Delta P$ is a direct measure for the specific viscosity of the polymer plug in the fluidic resistance as will be shown in the next paragraph. The delay volume in the lower branch is added for symmetry reasons. This principle is applied in a commercial viscosity detector [32] as well. That device is intended for use with conventional polymer chromatography systems and is therefore not directly suitable for integration with micromachined separation systems. Consequently, an alternative micromachined design using the Wheatstone bridge configuration [33] was developed.

\section{B. Wheatstone Bridge Response}

In this section the specific viscosity $\eta_{s p}$ from formula (1), which is the parameter we want to detect, is related to the differential pressure $\Delta P$ and the bridge pressure $P_{1}$. Time constants determining the speed of the system are identified as well. A schematic of the system is shown in Fig. 4. We can distinguish three parts in the total system: the separation channel including the injection, the measurement of the bridge pressure and the Wheatstone bridge. The injection and separation part can be represented by the fluidic resistances $R_{1}, R_{2}$ and $R_{3}$. The part of the separation channel that is used as injection region is represented by $R_{1}$. Resistance $R_{3}$ corresponds to slit 3 in Fig. 3 . The separation channel itself is modeled by $R_{2}$. Since in this paper we consider a stand-alone viscodetector, i.e., without a separation channel, but with an integrated structure for injection of a sample zone, we can assume that $R_{1}, R_{2} \ll R_{3}, R_{4}$. The pressure sensors are represented by capacitances $C_{1}$ and $C_{2}$, as we will be using membrane-type pressure sensors. In those sensors a deflection gives rise to a volume change under the membrane, which can be modeled by a hydraulic capacitance. The effect of an increase in viscosity due to a polymer peak is represented by an increase in fluidic resistance $\Delta R$.

When starting a measurement, an input pressure $P_{0}$ is applied. Assuming that initially $\Delta R \approx 0$, the response of the bridge pressure $P_{1}$ is

$$
P_{1}(t)=P_{0}\left(1-e^{\left(t / \tau_{1}\right)}\right) \text { in which } \tau_{1}=\left(R_{1}+R_{2}\right) C_{1} .
$$




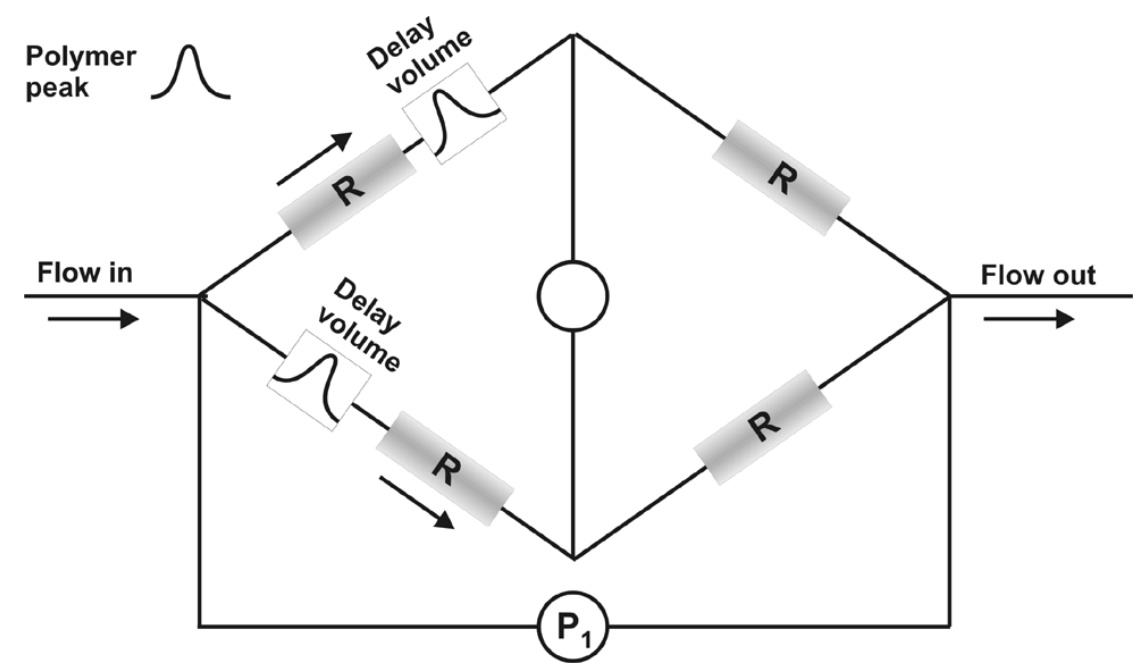

Fig. 3. Differential viscosity detection by using a Wheatstone bridge of fluidic resistances.

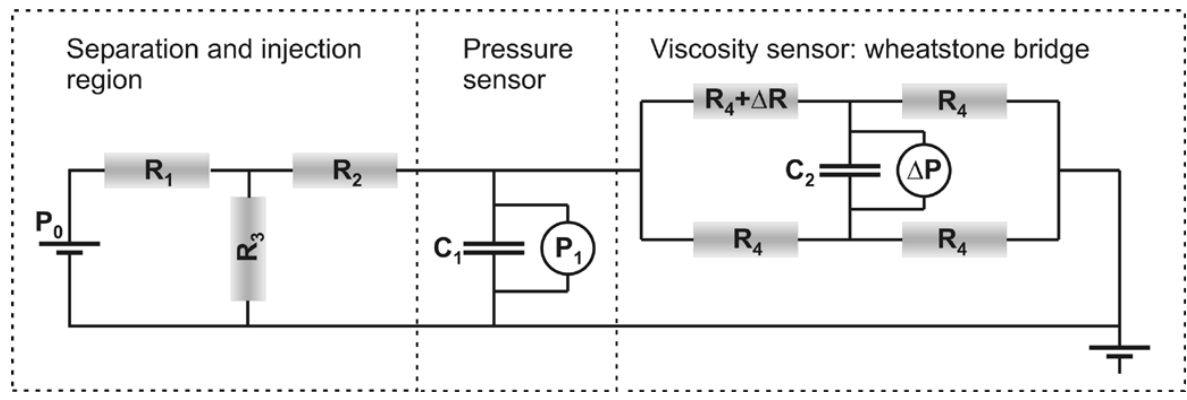

Fig. 4. Equivalent electrical network of a Wheatstone bridge viscosity detector.

The fluidic resistance of a channel is defined by the pressure drop divided by the volume flow. For a channel of rectangular cross-section and length $L_{R}$ for which the height $h \ll$ width $w$ the resistance $R$ is [34]

$$
R=\frac{12 \eta L_{R}}{w h^{3}} .
$$

Combination of (1) and (4) gives for $\Delta R$

$$
\Delta R=\eta_{s p} R_{4}=c[\eta] R_{4} .
$$

For a dynamic analysis of the response of $\Delta P$ on an increase in $\Delta R$ we assume $\Delta R \ll R_{4}$, which will generally be valid for dilute polymer solutions. Furthermore we model the concentration of the plug entering the bridge, and according to (5) also $\Delta R$, with a function that increases linearly from zero at $t=T_{1}$ to a constant value at $t=T_{2}$. This results in

$$
\begin{aligned}
& \Delta P(t)=\frac{\eta_{s p} P_{0}}{4 T_{2}}\left(1-e^{\left(t / \tau_{1}\right)}\right) \\
& \times \sum_{n=0}^{1}(-1)^{n} H\left(t-A_{n}\right)\left(t-A_{n}-\tau_{2}\left(1-e^{\left(\left(t-A_{n}\right) / \tau_{2}\right)}\right)\right.
\end{aligned}
$$

in which $H(t)$ is the Heaviside function and $A_{0}=T_{1}, A_{1}=$ $T_{1}+T_{2}$. This is shown in Fig. 5. It is clear from this equation that smaller time constants $\tau_{1}$ and $\tau_{2}$ will improve the speed of the system. For the case $t \diamond \infty$, in which the pressures $\Delta P$ and $P_{1}$ are constant (implying $P_{1}=P_{0}$ ), (6) can be simplified. For the following expression the exact form of $\Delta R(t)$ is not important.

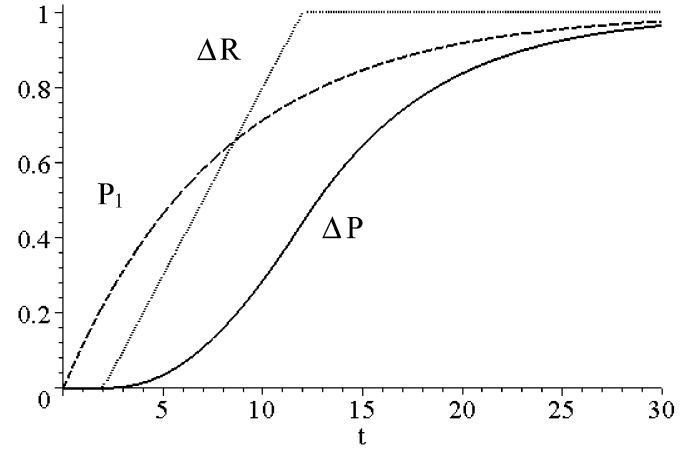

Fig. 5. The normalized response $\Delta P(t)$ of the system from Fig. 3 on a pressure step at $t=0$ and a $\Delta R$ for which $T_{1}=2 \mathrm{~s}$ and $T_{2}=10 \mathrm{~s}$. The time constants $\tau_{1}$ and $\tau_{2}$ are $8 \mathrm{~s}$ and $5 \mathrm{~s}$, respectively.

Since $t \diamond \infty$, the assumption $\Delta R \ll R_{4}$ and thus $\eta_{s p} \ll 1$ can be removed giving

$$
\eta_{s p}=\frac{4 \Delta P}{P_{0}-2 \Delta P} .
$$

This gives the desired expression for the specific viscosity $\eta_{s p}$ as a function of the bridge and the differential pressure.

\section{Membrane Pressure Sensing}

The detection speed of the system is mainly determined by the hydraulic capacitance of the differential pressure sensor, as this is the sensor that directly responds to a viscosity change. Its 
response time constant is proportional to the hydraulic capacitance $C$ defined by

$$
C=\frac{\partial V}{\partial P}
$$

in which $V$ is the volume displacement of the membrane. This displacement can be calculated from the deflection surface $v(x, y)$ of a membrane under pressure. Because we will be using microfabricated sensors an intrinsic stress in the membrane material will be present. Consequently, the expression given in [35] for the deflection surface of a membrane with an intrinsic stress is used.

Since the membrane deflection of this sensor is measured using the angular deflection of a laser beam, the sensitivity to pressure changes is determined by $d v / d x$. Combining a large deflection angle and a minimum capacitance means that the pressure sensing membrane must be both small and thin. The membrane thickness is limited by technological considerations. The space needed for the detection sets a lower limit on the membrane size.

\section{ThE Micro Viscosity DeteCtOR}

In order to be able to analyze the performance of the sensor, a stand-alone detector was designed, i.e., without a HDC separation channel. However, in order to ensure integration, the fabrication process was kept identical to the process used for the HDC chip described in [4]-[6]. This means that two different channel depths were defined in a silicon wafer and closed by bonding a Pyrex wafer on top. The smallest channel depth is the same one used for the HDC separation, which is $1 \mu \mathrm{m}$. The deeper channel depth can be chosen in the range $20-50 \mu \mathrm{m}$ depending on the viscometer requirements.

\section{A. Design}

Because an actual separation channel is not incorporated in this device, the injection structure is used to generate a viscosity transition similar to the one encountered at the end of a HDC separation channel. The injection structure is constructed in a flat, (1 $\mu \mathrm{m}$ high, $1 \mathrm{~mm}$ wide) wide channel part with the same cross-sectional dimensions as an HDC separation channel.

Since a minimum channel height of $1 \mu \mathrm{m}$ was used for the injection channel part preceding the bridge, the only way to create extra fluidic resistance is by narrowing the channel. This however disturbs the definition of the sample zone. In order to minimize dispersion, nozzle structures are added that guide the plug into the resistance channels. The nozzle shape is shown in Fig. 6. Simulation results regarding the performance of the nozzles will be published in a separate paper.

Directly after the injection the plug is split; one half of the flow enters the measurement resistance, the other half has to be absorbed by a delay volume that has negligible fluidic resistance compared to the bridge resistance. This is achieved by creating a deeper channel structure.

The delay volumes must be large enough to contain all fractions created during one separation run. The maximum spatial separation in an on-chip HDC separation with a $10 \mathrm{~cm}$ long separation channel is estimated to be $20 \mathrm{~mm}$, which corresponds to

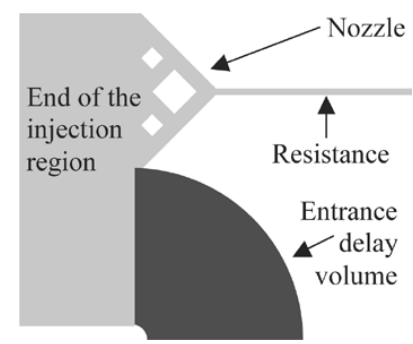

Fig. 6. Top view of the transition region from the injection part to the entrance of the bridge, consisting of a nozzle leading to a fluidic resistance and a deeper $(40 \mu \mathrm{m})$ delay volume. The lighter region is $1 \mu \mathrm{m}$ deep.

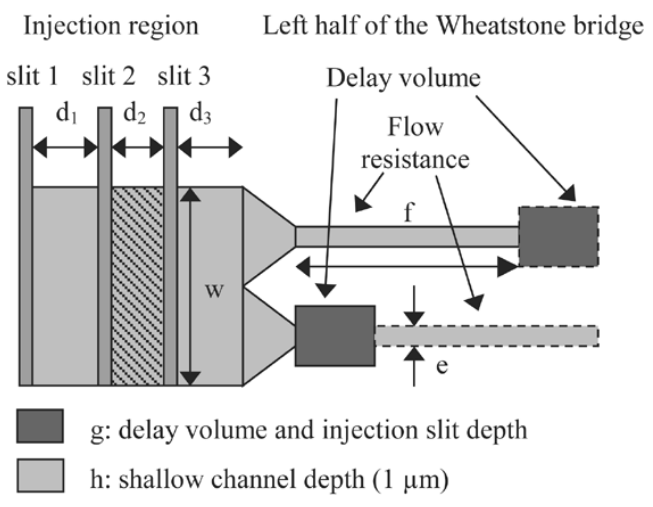

Fig. 7. Top view of the injection region and the first half of the bridge. The lighter regions are $1 \mu \mathrm{m}$ deep; the darker regions are $40 \mu \mathrm{m}$ deep. The dashed region between slit 2 and 3 is the region where the viscosity plug is defined using the injection scheme described in [10].

a volume of $20 \mathrm{nl}$. For a delay volume depth of $40 \mu \mathrm{m}$ and a width of $500 \mu \mathrm{m}$, a minimum length of $1 \mathrm{~mm}$ is required. This can be increased in order to better fit the complete design.

According to formula (2) the specific viscosity strongly depends on the polymer mass $M$. The detector is designed for an accuracy in specific viscosity of $10^{-4}$ which means that a concentration of $3 \mu \mathrm{g} / \mathrm{ml}$ polystyrene of mass $M=10^{5}$ Dalton in toluene can just be detected. This concentration is $10 \%$ of the expected peak concentration in a typical polymer separation. Toluene produces a background constant viscosity $\eta_{0}$ of $5.5 \times 10^{2} \mu \mathrm{Pas}$, resulting in a required sensitivity of $0.055 \mu$ Pas. This should be translated to dimensions for the flow resistances as shown in Fig. 7. The following effects determine the required dimensions of the resistance channels.

1) The resolution in $\eta_{s p}$ is determined by the relative error in the differential pressure measurement. Consequently, the total differential pressure should be maximized by maximizing the resistances $R_{4}$.

2) To obtain sufficient spatial resolution of the peaks, the internal volume of the resistances should be small compared to the volume of the viscosity plug.

3) The velocity in the resistance channels should be limited to $v_{R}<0.5 \mathrm{~mm} / \mathrm{s}$ because of the shear-thinning effects mentioned before.

Combination of these requirements leads to the sensor dimensions shown in Table I. In order to obtain the desired $\Delta \eta_{s p}=$ $10^{-4}$ a resolution in differential pressure sensing of $\Delta(\Delta P)=$ $0.6 \mathrm{~Pa}$ is needed for this configuration. The hydraulic capacitance of the differential sensor can be estimated using the required value for the time constant $\tau_{2}=R_{4} C_{2}$ and the dimen- 
TABLE I

DIMENSIONS IN THE VISCOMETER DESIGN

\begin{tabular}{l|l|l|l}
\hline$d_{1}$ & $1 \mathrm{~mm}$ & $g$ & $40 \mu \mathrm{m}$ \\
\hline$d_{2}$ & $1.2 \mathrm{~mm}$ & $h$ & $1 \mu \mathrm{m}$ \\
\hline$d_{3}$ & $0.6 \mathrm{~mm}$ & $w$ & $1 \mathrm{~mm}$ \\
\hline$e$ & $20 \mu \mathrm{m}$ & $v_{\text {channel }}$ & $0.02 \mathrm{~mm} / \mathrm{s}$ \\
\hline$f$ & $3.8 \mathrm{~mm}$ & $v_{R}$ & $0.5 \mathrm{~mm} / \mathrm{s}$ \\
\hline
\end{tabular}

sions for $R_{4}$ from Table I. Considering a maximum velocity of $0.5 \mathrm{~mm} / \mathrm{s}$ and a sample zone length of $1.2 \mathrm{~mm}$ a $\tau_{2}<0.15 \mathrm{~s}$ is needed resulting in $C_{2}<10^{-19} \mathrm{~m}^{3} / \mathrm{Pa}$.

As we could not find a commercial pressure sensor that combines a resolution of $0.6 \mathrm{~Pa}$ with a hydraulic capacitance of $10^{-19} \mathrm{~m}^{3} / \mathrm{Pa}$ we developed a membrane pressure sensor consisting of a silicon nitride membrane. The silicon nitride membrane is fixed inside a $\mathrm{KOH}$-etched silicon structure, which also incorporates a channel connecting the backside of the membrane to one of the differential pressure ports. The membrane itself is aligned to the other differential pressure port. The channel defined in the silicon wafer is closed by anodically bonding a glass wafer on top. As the connection of the Wheatstone bridge and the pressure sensor should be solvent resistant and should not induce any additional hydraulic capacitance, the sensor is anodically bonded to the channel chip.

The angular deflection of the membrane was measured optically using a laser beam that was focused at the side of the membrane, thus giving a maximum angular deflection. The beam shift was detected using a split photodiode. The sensor is described in more detail in [36].

The hydraulic capacitance of the sensor for $P_{1}$ can be much larger since it is not connected to the pressure source through a high fluidic resistance, as is the case for $P_{2}$. Consequently, a commercial pressure sensor can be used, such as the Honeywell 24PC series.

\section{B. Fabrication}

The fabrication sequence of the channel structure is basically the same as the one that was used for fabrication of the HDC chip described in [4]. Silicon wafers are thermally oxidized creating a $1 \mu \mathrm{m}$ oxide layer. The first masking layer is used for local BHF etching of the silicon oxide layer, defining the injection channel and the resistances. A new lithography step defines the etch openings for the injection slits and the delay volumes. These are etched to a depth of approximately $40 \mu \mathrm{m}$ using cryogenic Deep Reactive Ion Etching [25], [26]. A SEM picture of the channel structure in silicon is shown in Fig. 8.

Polished Pyrex wafers are provided with contact pads for the Honeywell pressure sensor by sputtering of $20 \mathrm{~nm} \mathrm{Cr}$ followed by $200 \mathrm{~nm}$ Pt. Through-holes are defined using powderblasting [39]-[41]. The Pyrex and silicon wafers are fusion-bonded and annealed at $425{ }^{\circ} \mathrm{C}$.

The differential pressure sensor, of which the fabrication is described more extensively in [36], is bonded after dicing of the chips containing the channel structure. For the pressure sensor a $206 \times 206 \mu \mathrm{m}$ silicon nitride membrane of $470 \pm 30 \mathrm{~nm}$ thickness is used. In order to facilitate bonding and contrary to [36], no metal layer is sputtered onto the silicon nitride membrane. Bonding is performed at $400{ }^{\circ} \mathrm{C}$ and $1.2 \mathrm{kV}$ for $1 \mathrm{~h}$.

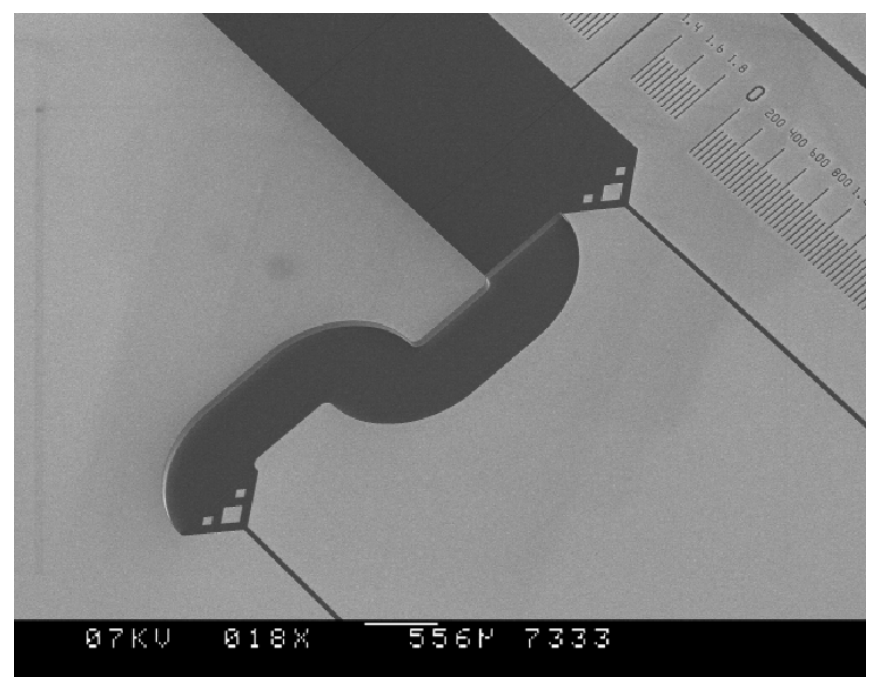

Fig. 8. SEM picture of a part of the viscosity detector. Top left the $1 \mu \mathrm{m}$ deep injection part is visible, connected to two narrower fluidic resistances by a nozzle and a deeper delay volume.

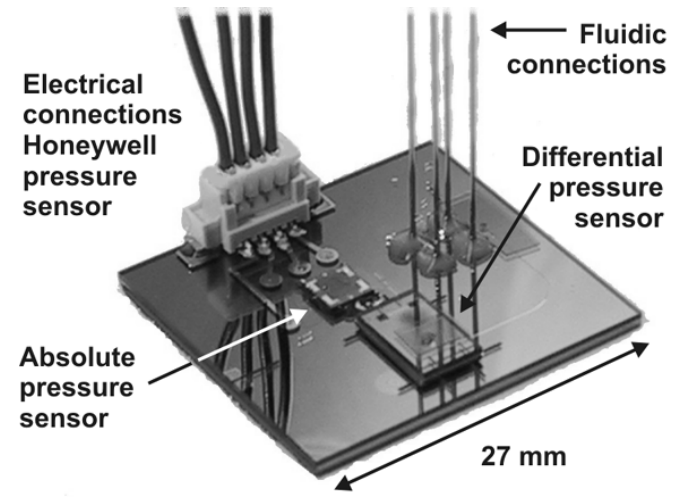

Fig. 9. Close-up of a ready-to-use viscosity detector.

The Honeywell sensor is glued to the chip using epoxy glue together with an electrical connector that is connected to the metal layer on the glass using conductive silver glue (Leitsilber, Degussa-Huls Benelux BV, Amsterdam). The Honeywell sensor itself is electrically connected to the metal layer using wire bonds.

For filling of the sensor a recipe is developed that uses the good solubility of carbon dioxide in basic solutions. Because this easily dissolves any trapped bubbles, no particular attention was paid to minimizing dead volumes at this stage. In daily use however, it is very important to prevent bubbles getting trapped underneath the pressure sensor membranes. For this purpose a flushing channel is present in the micromachined differential sensor, which is connected to the top side of the membrane. For the Honeywell sensor however, no flushing means is present yet.

After filling fused silica capillaries are connected using epoxy glue. A picture of the finished chip is shown in Fig. 9.

\section{CHARACTERIZATION}

\section{A. The Stand-Alone Differential Pressure Sensor}

The characterization of a stand-alone version of the differential pressure sensor is described extensively in [36]. A sensing resolution of $2 \mathrm{~Pa}$ was estimated for a $125 \times 125 \mu \mathrm{m}, 200-\mathrm{nm}-$ thick silicon nitride membrane $\left(C=4 \times 10^{-19} \mathrm{~m}^{3} / \mathrm{Pa}\right)$ that was coated with a thin metal layer. 
For the stand-alone viscometer a different, $206 \times 206 \mu \mathrm{m}$ and $470 \pm 30 \mathrm{~nm}$ thick membrane $\left(C=1.4 \pm 0.2 \times 10^{-18} \mathrm{~m}^{3} / \mathrm{Pa}\right)$ is used, which is theoretically three times less sensitive. Additionally, there was no metal layer on the membrane. It was therefore tested using liquids with a larger viscosity difference.

\section{B. Test Setup}

The test setup uses a digital pressure controller (Bronkhorst P-612C, Veenendaal, The Netherlands) that is capable of individually pressurizing with He-gas two home-made pressure vessels filled with the buffer solution. For addressing the pressure vessels a switch-board containing 4 gas valves is used (Swagelok B41S2, Solon, USA). Each pressure vessel is coupled to the capillaries that are glued to the injection slits by a 6-port two-way valve (Valco C6W, Houston, TX). These valves enable the use of the injection scheme from [10].

The Honeywell sensor is supplied with $10 \mathrm{~V}$ by a Delta Elektronika E018-0.6D (Zierikzee, The Netherlands) voltage supply. The output voltage is recorded using an HP 34401A multimeter (Palo Alto, CA).

The membrane deflection of the differential pressure sensor is measured optically. For that purpose a laser diode operating at a wavelength of $670 \mathrm{~nm}$ (supply voltage $=4 \mathrm{~V}_{\mathrm{pp}}$ ) is modulated with a block wave at $5010 \mathrm{~Hz}$. The laser beam is focused at the membrane using a $25 \mathrm{~mm}$ focal length lens. The output is recorded by a split photodiode coupled to a lock-in amplifier (Stanford Research Systems SR830 DSP, Sunnyvale, USA). The lock-in amplifier gives an output voltage $V_{\text {lock-in }}$ which is proportional to the differential photodiode output. All signals from the digital pressure controller, the Honeywell output and the lock-in amplifier are collected at a sample rate of $0.5 \mathrm{~Hz}$ using a HPVEE program.

\section{The Performance of the Sensor}

1) Introduction: The performance of the sensor consists of two parts: the resolution in the measurement of the specific viscosity $\Delta \eta_{s p}$ and the speed of the system that is mainly determined by the time constant $\tau_{2}$. Because the detector initially is designed as a stand-alone sensor, the performance can be tested by injecting a plug of liquid with a known viscosity into another known liquid that serves as the running buffer, thus creating a known viscosity difference expressed as a specific viscosity $\eta_{s p}$.

In order to determine $\Delta \eta_{s p}$ the resolution in the pressure sensing $\Delta(\Delta P)$ must be known. They can be related by using (7) and observing that $\Delta(\Delta P) \ll P_{0}$ :

$$
\Delta \eta_{s p}=\frac{4 \Delta(\Delta P)}{P_{0, \max }} .
$$

The maximum bridge pressure $P_{0, \max }$ follows from the requirement that the velocity in the fluidic resistance cannot exceed 0.5 $\mathrm{mm} / \mathrm{s}$. The resolution in $\Delta P$ can be estimated from the resolution in the lock-in amplifier output voltage $V_{\text {lock-in }}$. We define

$$
\Delta P=k V_{\text {lock-in }}
$$

in which $k$ does not necessarily have to be a constant. Combination of (7) and (10) gives

$$
V_{\text {lock-in }}=\frac{\eta_{s p}}{4 k\left(1+\frac{1}{2} \eta_{s p}\right)} P_{0} .
$$

TABLE II

Viscosities [42] OF THE LIQUids THAT WERE USED IN TESTING THE VISCOSITY DETECTOR AT $T=23^{\circ} \mathrm{C}$. THE BINARY DIFFUSION Coefficients [43] IN Water ARE TAKen at $T=25^{\circ} \mathrm{C}$

\begin{tabular}{l|l|l|l}
\hline Compound & $\begin{array}{l}\text { Viscosity } \\
(\mathrm{mPa} *)\end{array}$ & $\begin{array}{l}\text { Specific } \\
\text { viscosity } \eta_{s p}\end{array}$ & $\begin{array}{l}\text { Binary diffusion } \\
\text { coefficient }\left(10^{-9} \mathrm{~m}^{2} / \mathrm{s}\right)\end{array}$ \\
\hline Methanol & 0.57 & 0.61 & 1.54 \\
\hline Ethanol & 1.13 & 1.20 & 1.22 \\
\hline DI water & 0.94 & - & - \\
\hline
\end{tabular}

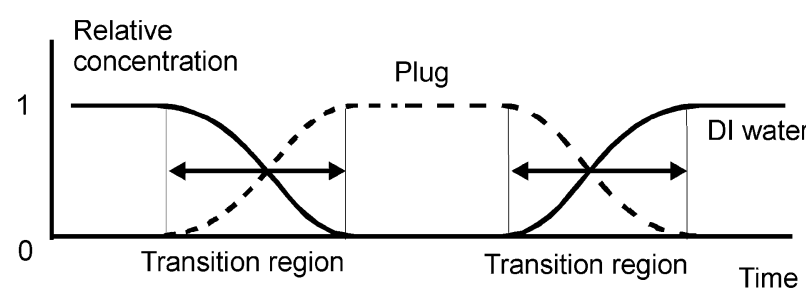

Fig. 10. schematic of the concentration profile of the injected plug.

Hence, $k$ can be determined from a graph of lock-in amplifier data obtained at different run pressures for a known viscosity plug. Equation (10) can be used to calculate $\Delta(\Delta P)$. Subsequently, the resolution $\Delta \eta_{s p}$ can be estimated using (9).

As the sensor is filled with deionized (DI) water in the final stage of the fabrication process DI water is used as the baseline fluid. Since for a polymer viscosity detector the viscosity differences that have to be measured are small the viscosity of the liquid that is injected has to be close to that of water. For this reason we choose methanol and ethanol as calibration substances. Both methanol and ethanol easily mix with water. Although at first sight nonmiscible fluids enable a better definition of a viscosity step, surface tension effects could complicate the injection. Therefore fluids that easily mix with water are preferred.

The difference in viscosity relative to DI water is expressed in the specific viscosity $\eta_{s p}$ from (1) as shown in Table II. Although this formula strictly speaking is only used for dilute polymer solutions, expression of the detection performance as a specific viscosity enables a better extension to the use of a viscosity detector in polymer chromatography.

Because of diffusion and dispersion in the injection slits it is impossible to inject a plug that has an infinitely steep transition in viscosity (see Fig. 10). If this affects the detection depends on the size of the transition region relative to the spatial resolution. The size of transition region depends on the geometry of the injection region, the injection time and the binary diffusion coefficients in water (see Table II).

Visualization is difficult because the proximity of the injection region and the capillaries prevents use of a fluorescence microscope. Therefore the precise shape of the concentration profile is unknown. Consequently, formula (6) cannot be used so that the time constant $\tau_{2}$ cannot be determined experimentally.

The existence of a transition region has an additional effect. This is shown in Fig. 11 where the viscosity of a mixture of ethanol or methanol with water shows a maximum that is larger than the individual viscosities. This effect will be visible if the 


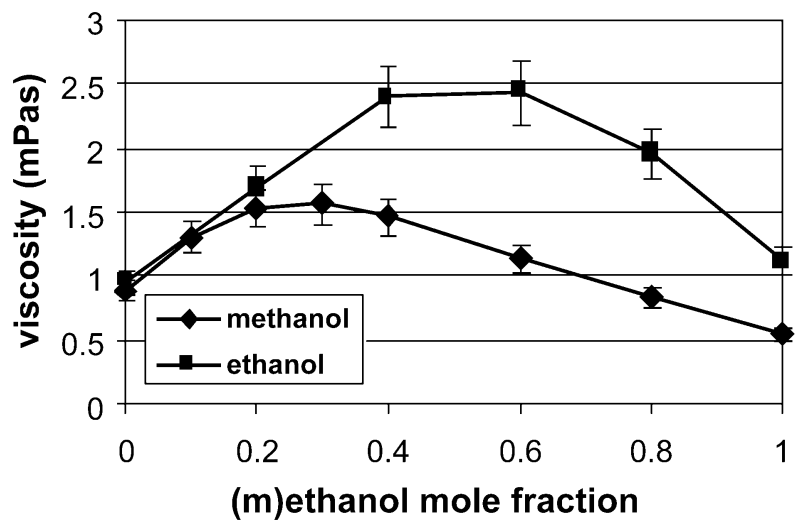

Fig. 11. the viscosity of mixtures of ethanol/DI water and methanol/DI water at various mole fractions. The ethanol/DI water data were obtained using a Contraves LS40 reometer, the data for methanol/DI were taken from [44].

transition region is large and the system fast enough to detect these sudden viscosity changes.

2) Resolution of the Specific Viscosity Measurement: The output from the absolute pressure sensor $\left(P_{1}\right)$ and from the lock-in amplifier output ( $\left.V_{\text {lock-in }}\right)$, are measured in time. From the resulting graph of the lock-in output data for different pressures $P_{1}$ the resolution can be derived using formulas (9)-(11).

Methanol Injection

A typical result for a run at $P_{0}=0.43$ bar using a methanol plug that was injected for $1 \mathrm{~min}$ at 2 bar is shown in Fig. 12 . The viscosity is higher at the boundaries of the plug, where mixing of methanol and water increases the viscosity, as was shown in Fig. 11. The methanol viscosity, which is lower than the water viscosity should give a negative signal for the output of the lock-in amplifier. This is however not the case. First of all, this is caused by the relatively large transition regions. An estimate of the size of the transition regions can be made by calculating the diffusion distance $\sigma$ by

$$
\sigma=\sqrt{2 D_{12} t_{\mathrm{inj}}}
$$

Using the value of Table II and the injection time of $60 \mathrm{~s}$ a diffusion distance of $430 \mu \mathrm{m}$ results, which is quite considerable when compared to the injection region of $1.2 \mathrm{~mm}$. Measurement is further influenced by the fact that the volume of the resistance is about one-fourteenth of the injection volume. Thus the signal always represents and average value. Furthermore, the plug profile could be disturbed somewhat when switching the valves from injection to run, as was illustrated in [10].

The reasons mentioned above, combined with a finite (slow) response time of the differential transducer, can very well explain the fact that the signal from Fig. 12 does not reach the value for a $100 \%$ methanol viscosity before the trailing transition region enters the measurement resistance.

Even for different injection times and injection pressures and different run pressures, no stable value for the methanol viscosity could be measured. Consequently it is not possible to derive any quantitative data from these measurements as the concentration profile in the transition region between methanol and water is not known.

\section{Ethanol Injection}

When ethanol was injected, the same mixing effect could be observed. However, this could be avoided by shortening the in-

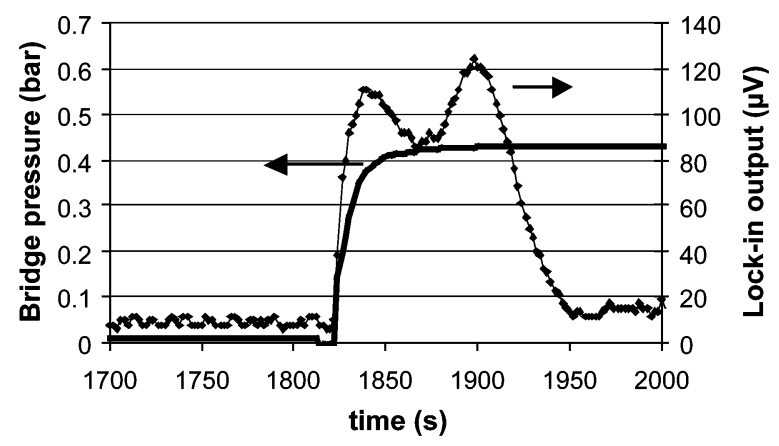

Fig. 12. injection of a methanol plug. The mixing effect from Fig. 10 is clearly visible at the leading and trailing edges of the plug.

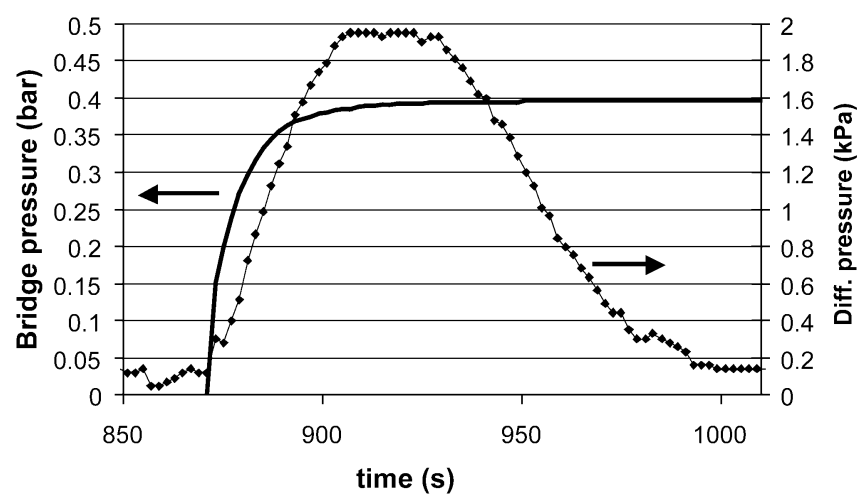

Fig. 13. injection of an ethanol plug that was run at 0.39 bar. A viscosity peak is clearly visible.

jection time thus limiting the diffusional broadening of the transition zone. Compared to methanol this effect was reduced because of the lower diffusion coefficient for ethanol. The reduction of the mixing effect for ethanol can also be explained by the direction of the viscosity change. As mixing will mainly increase the viscosity and since the ethanol viscosity is higher than that of water, the mixing effect will be masked by the ethanol signal. As for methanol a decrease in viscosity should be observed, the mixing effect is much better visible.

It turned out that injection at 2.2 bar for 1 min sufficiently limited the size of the transition region. The resulting output from the lock-in amplifier and the Honeywell sensor $\left(P_{1}\right)$ from a plug that was run at $P_{0}=0.39$ bar is shown in Fig. 13 .

The part of the graph we are interested in is the constant part between $t=900$ and $930 \mathrm{~s}$. The delay in the pressure response of the Honeywell sensor that was described by the time constant $\tau_{1}$ causes a bridge input pressure $P_{1}$ that is, at the onset of the constant part of the lock-in output, maximum 5\% lower than the applied pressure $P_{0}$ for all measurements performed. As (7) is derived for $t \diamond \infty$, an additional error is introduced by this same percentage. From bridge pressure response curves as shown in Fig. 13 a value for $\tau_{1}$ can be determined. From measurements performed at 4 different pressures $(0.26$ bar, 0.39 bar, 0.79 bar and 0.98 bar) a value of $\tau_{1}=7.4 \pm 0.7 \mathrm{~s}$ is deduced. This can be translated to a hydraulic capacitance for the Honeywell pressure sensor of $C_{1}=(2.3 \pm 0.3) \times 10^{-16} \mathrm{~m}^{3} / \mathrm{Pa}$. As mentioned before, $\tau_{2}$ and thus $C_{2}$ cannot be determined because of the unknown concentration profile of the plug.

The maximum lock-in amplifier output for injection of ethanol plugs in DI water at four different pressures: 0.26 bar, 


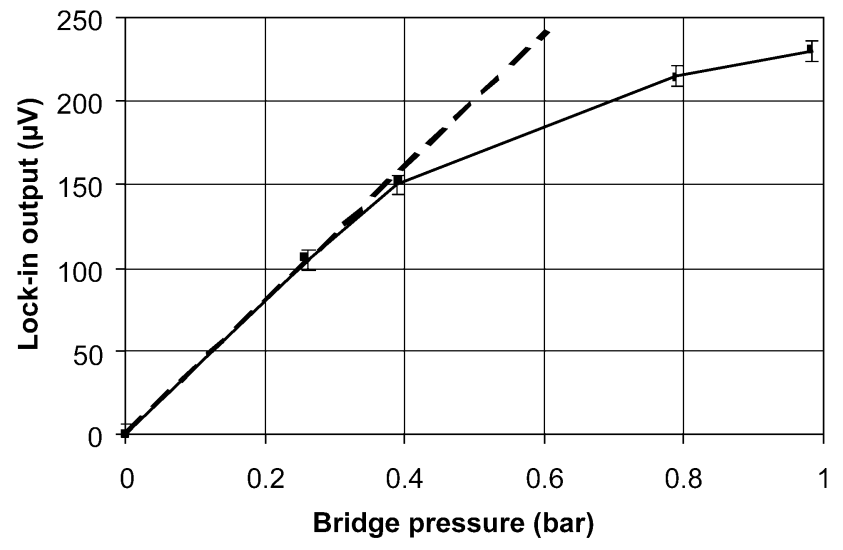

Fig. 14. maximum lock-in amplifier output against the bridge pressure for ethanol injected at four different pressures.

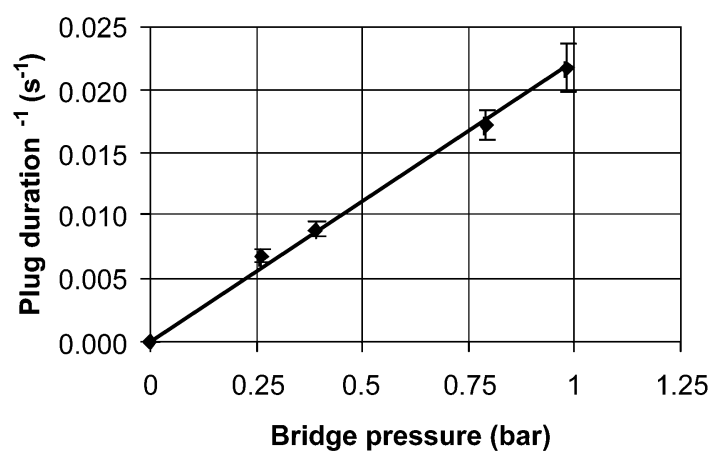

Fig. 15. The inverse duration of the viscosity plugs for different run pressures shows a linear trend indicating that the pressure and the velocity in the channels are proportional.

0.39 bar, 0.79 bar, and 0.98 bar is shown in Fig. 14. Because we are dealing with relatively large pressure differences $\Delta P$ the response is not linear with $P_{1}$ (and thus with $\Delta P$ ). Consequently for operation as a viscosity detector for polymer separations we are interested in the range where $\Delta P$ and thus $V_{\text {lock-in }}$ is small. For this region $k$ is a constant: $k=11.3 \pm 0.6 \mathrm{~Pa} / \mu \mathrm{V}$.

The noise in the lock-in output signal is $\Delta V_{\text {lock-in }}=3 \mu \mathrm{V}$ which is independent of the pressure on the bridge. Equation (10) gives $\Delta(\Delta P)=34 \pm 2 \mathrm{~Pa}$. The maximum value of the bridge pressure $\left(P_{0, \max }\right)$ is determined by the maximum velocity in the resistances $v_{R, \max }=0.5 \mathrm{~mm} / \mathrm{s}$, which can be calculated to be $P_{0, \max }=0.45 \pm 0.1$ bar. With (9) the resolution of the viscosity sensing is $\Delta \eta_{s p}=3.0 \pm 0.3 * 10^{-3}$.

The velocity is estimated using the measured bridge pressure and the calculated fluidic resistance. The validity of this approach can be determined by observing that the bridge pressure $P_{0}$ has to be inversely proportional to the time duration of the plug $t_{\text {plug. }}$. From this a plug length can be calculated. The slope in Fig. 15 gives a plug length of $l_{p}=2.1 \mathrm{~mm}$, independent of the driving pressure. The linearity of Fig. 15 qualitatively validates the velocity calculations. The injection length of $2.1 \mathrm{~mm}$ is larger than the injection region length $d_{2}$ of $1.2 \mathrm{~mm}$ (see Fig. 8). The constant peak width points to a peak broadening that occurs mainly during injection, by a combination of diffusive and convective mixing.

Altogether this shows that a functional prototype viscosity detector has been created. Although the resolution is not as good
TABLE III

MAIN Results FOR THE PROTOTYPE Viscosity DETECTOR

\begin{tabular}{l|l}
\hline$\Delta V_{\text {lock-in }}$ & $3 \mu \mathrm{V}$ \\
\hline$\Delta(\Delta P)$ & $34 \pm 2 \mathrm{~Pa}$ \\
\hline$\eta \Delta_{s p}$ & $3.0 \pm 0.3 * 10^{-3}$ \\
\hline$\tau_{2 \text { (theoretical) }}$ & $3 \mathrm{~s}$ \\
\hline
\end{tabular}

as the desired $\Delta \eta_{s p}=10^{-4}$ there are several possibilities for improvement that will be discussed in Section V.

\section{DISCUSSION}

\section{A. Discussion of the Characterization Results}

A summary of the results for this viscosity detector is given in Table III. Comparing the realized resolution in specific viscosity of $3.0 \times 10^{-3}$ to the desired value of $10^{-4}$, shows that this device needs to be improved for use as a detector for on-chip HDC. This is due to the fact that the resolution in the differential pressure sensing was $\Delta(\Delta P) \approx 34 \mathrm{~Pa}$ instead of $2 \mathrm{~Pa}$, as was the case for the stand-alone pressure sensing membranes. This is partially due to the fact that a theoretically 3 times less sensitive membrane was used in the integrated detector compared to the stand-alone sensors.

Other factors that can improve sensitivity are as follows.

- $\quad$ Use of a more powerful and more stable laser system as the one that was used for the stand-alone pressure sensors instead of the laser diode applied with the integrated viscosity detector.

- Increase of the reflectance of the silicon nitride membrane as was done with the stand-alone sensors.

- $\quad$ Resizing the membrane of the pressure sensor $\Delta P$. Taking a smaller and thinner membrane would enable a simultaneous improvement of the hydraulic capacitance and the sensitivity. Replacing the membrane $(206 \times 206 \mu \mathrm{m}$, thickness $470 \mathrm{~nm})$ by a $100 \times 100$ $\mu \mathrm{m}, 55 \mathrm{~nm}$ thick membrane (which is technologically feasible [45]) would meet the requirements for the hydraulic capacitance and give a five-fold improvement in sensitivity.

\section{B. Scaling}

It is useful to calculate how the performance scales if the detector would be coupled to a conventional liquid chromatography (LC) system. As the design constraints imposed by the HDC separation channel do not apply, the geometry can be rescaled at will. A scaling analysis gives for the bridge pressure $P_{1}$

$$
P_{1} \sim \frac{\eta V_{s}}{\varphi_{0}} .
$$

If we assume a comparable linear speed in the system, the volume flow $\Phi_{0}$ and sample volume $V_{s}$ both scale with the column area. Consequently, an increase in column area would mean that $P_{1}$ remains approximately equal. Given the fact that $\Phi_{0}$ increases, the fluidic resistance must decrease. For a comparable response time this means that the hydraulic capacitance of 
TABLE IV

LIST OF VARIABLES

\begin{tabular}{|c|c|c|}
\hline Name & Variable & Unit \\
\hline polymer concentration & $c$ & $\mathrm{~kg} / \mathrm{l}$ \\
\hline hydraulic capacitance pressure sensor $\mathrm{P}_{1}$ & $C_{l}$ & $m^{3} / P a$ \\
\hline hydraulic capacitance pressure sensor $\Delta \mathrm{P}$ & $C_{2}$ & $m^{3} / P a$ \\
\hline distance between slit 1 and 2 & $d_{1}$ & $m$ \\
\hline distance between slit 2 and 3 & $d_{2}$ & $m$ \\
\hline distance between slit 3 and bridge & $d_{3}$ & $m$ \\
\hline binary diffusion coefficient & $D_{12}$ & $\mathrm{~m}^{2} / \mathrm{s}$ \\
\hline resistance width & $e$ & $m$ \\
\hline resistance length & $f$ & $m$ \\
\hline delay volume depth & $g$ & $m$ \\
\hline height separation channel & $h$ & $m$ \\
\hline Mark-Houwink constant 1 & $k$ & $m l^{*} \mathrm{~mol} / \mathrm{g}^{2}$ \\
\hline Mark-Houwink constant 2 & $a$ & - \\
\hline plug length & $\overline{l_{p}}$ & $m$ \\
\hline length fluidic resistance & $L_{R}$ & $m$ \\
\hline polymer molecular mass & $M$ & $\mathrm{~g} / \mathrm{mol}=\mathrm{Da}$ \\
\hline pressure & $P$ & $P a$ \\
\hline input pressure & $P_{0}$ & $P a$ \\
\hline maximum allowable input pressure & $P_{0, \max }$ & $P a$ \\
\hline bridge pressure & $P_{1}$ & $P a$ \\
\hline bridge differential pressure & $\Delta P$ & $P a$ \\
\hline resolution in $\Delta \mathrm{P}$ & $\Delta(\Delta P)$ & $P a$ \\
\hline fluidic resistance & $R$ & $P a * s / m^{3}$ \\
\hline fluidic resistance change & $\Delta R$ & $P a^{*} s / m^{3}$ \\
\hline complex frequency & $s$ & $\mathrm{~Hz}$ \\
\hline time & $t$ & $s$ \\
\hline onset of the resistance change $\Delta \mathrm{R}$ & $T_{1}$ & $s$ \\
\hline end of the resistance change $\Delta \mathrm{R}$ & $T_{2}$ & $s$ \\
\hline plug duration & $t_{p}$ & $s$ \\
\hline membrane volume displacement & $V$ & $m^{3}$ \\
\hline membrane deflection & $v(x, y)$ & $m$ \\
\hline velocity separation channel & $v_{\text {channel }}$ & $\mathrm{m} / \mathrm{s}$ \\
\hline velocity resistances & $v_{R}$ & $m / s$ \\
\hline sample volume & $V_{s}$ & $m^{3}$ \\
\hline width separation channel & $w$ & $m$ \\
\hline noise in the lock-in amplifier output voltage & $\Delta V_{\text {lock-in }}$ & $V$ \\
\hline viscosity & $\eta$ & $P a *_{s}$ \\
\hline intrinsic viscosity & {$[\eta]$} & $\mathrm{l} / \mathrm{kg}$ \\
\hline solvent viscosity & $\eta_{0}$ & $P a^{*} s$ \\
\hline specific viscosity & $\eta_{s p}$ & - \\
\hline resolution in specific viscosity & $\Delta \eta_{s p}$ & - \\
\hline injection time & $t_{i n j}$ & $s$ \\
\hline time constant pressure sensor $\mathrm{P}_{1}$ & $\tau_{l}$ & $s$ \\
\hline time constant pressure sensor $\Delta \mathrm{P}$ & $\tau_{2}$ & $s$ \\
\hline volume flow & $\Phi_{0}$ & $\mathrm{~m}^{3} / \mathrm{s}$ \\
\hline
\end{tabular}

the membrane pressure sensor can be enlarged, enabling a more sensitive measurement of the differential pressure. Altogether the resolution of the viscosity detector is increased for larger LC techniques.

\section{CONCLUSION}

A functional viscosity detector was manufactured and tested that is suitable for integration with an on-chip hydrodynamic chromatography system. Using a nonoptimized system, differential viscosity sensing was demonstrated leading to a resolution in specific viscosity of $3.0 \times 10^{-3}$. Sufficient possibilities for improvement exist in order to obtain the desired resolution of $10^{-4}$. Furthermore it is shown theoretically that the scaling behavior of this system is beneficial for larger, conventional polymer separation systems. This could enable viscosity detection for LC systems employing sample volumes that are too small for conventional viscosity detectors.

\section{ACKNOWLEDGMENT}

The authors wish to express their gratitude to M. Duits for help with the measurements of the viscosity of the ethanol/DI water mixture. This research was performed within the STW project "Hydrodynamic chromatography in integrated micromachined separation systems", in a cooperation of the University of Twente and the University of Amsterdam.

\section{REFERENCES}

[1] W. J. Lough and I. W. Wainer, High Performance Liquid Chromatography: Fundamentals Principles and Practice. London, U.K.: Blackie Academic and Professional, 1996. 
[2] H. Pasch and B. Trathnigg, HPLC of Polymers. Berlin, Germany: Springer, 1998, pp. 31-39.

[3] J. Brandrup and E. Immergut, Polymer Handbook. London, U.K.: Wiley, 1974.

[4] M. T. Blom, E. Chmela, J. G. E. Gardeniers, R. Tijssen, M. Elwenspoek, and A. van den Berg, "Design and fabrication of a hydrodynamic chromatography chip," Sens. Actuators B, Chem., vol. 82, pp. $111-116,2002$.

[5] E. Chmela, M. T. Blom, J. G. E. Gardeniers, A. van den Berg, and R. Tijssen, "A chip system for size separation of macromolecules and particles by hydrodynamic chromatography," Anal. Chem., vol. 74, no. 14, pp. 3470-3475, 2002.

[6] M. T. Blom, E. Chmela, R. E. Oosterbroek, R. Tijssen, and A. van den Berg, "On-chip hydrodynamic chromatography separation and detection of nanoparticles and biomolecules," Anal. Chem., vol. 75, no. 24, pp. 6761-6768.

[7] R. Tijssen, J. P. A. Bleumer, and M. E. van Kreveld, "Separation by flow (hydrodynamic chromatography) of macromolecules performed in open microcapillary tubes," J. Chromatogr., vol. 260, pp. 297-304, 1983.

[8] R. Tijssen, J. Bos, and M. E. van Kreveld, "Hydrodynamic chromatography of macromolecules in open microcapillary tubes," Anal. Chem., vol. 58, pp. 3036-3044, 1986.

[9] G. Stegeman, A. C. van Asten, J. C. Kraak, H. Poppe, and R. Tijssen, "Comparison of resolving power and separation time in thermal field-flow fractionation, hydrodynamic chromatography, and size-exclusion chromatography," Anal. Chem., vol. 66, pp. 1147-1160, 1994.

[10] E. Chmela, M. T. Blom, J. G. E. Gardeniers, A. van den Berg, and R. Tijssen, "A pressure driven injection system for an ultra-flat chromatographic microchannel," Lab-On-A-Chip, vol. 2, pp. 235-241, 2002.

[11] H. A. Barnes, J. F. Hutton, and K. Walters, An Introduction to Rheology. Amsterdam: Elsevier, 1989, pp. 16-23.

[12] T. A. Chamberlin and H. E. Tuinstra, "Construction and testing of a specific viscosity detector for size exclusion chromatography," J. Appl. Polymer Sci., vol. 35, pp. 1667-1682, 1988.

[13] R. E. Oosterbroek, T. S. J. Lammerink, J. W. Berenschot, A. van den Berg, and M. C. Elwenspoek, "Designing, realization and characterization of a novel capacitive pressure/flow sensor," in Proc. Transducers, Chicago, IL, 1997, pp. 151-154.

[14] D. Roche, C. Richard, L. Eyraud, and C. Audoly, "Piezoelectric bimorph bending sensor for shear-stress measurement in fluid flow," Sens. Actuators A, Phys., vol. 55, pp. 157-162, 1996.

[15] C. Liu, Y. C. Tai, J. B. Huang, and C. M. Ho, "Surface micromachined thermal shear stress sensor," in Proc. MEMS, Chicago, IL, 1994, pp. $9-12$.

[16] F. Jiang, Y. C. Tai, J. B. Huang, and C. M. Ho, "Polysilicon structures for shear stress sensors," in IEEE TENCON, Hong Kong, 1995, pp. 12-15.

[17] F. Jiang, Y. C. Tai, B. Gupta, R. Goodman, S. Tung, J. B. Huang, and C. M. Ho, "A surface-micromachined shear stress imager," in Proc. MEMS, San Diego, CA, 1996, pp. 110-115.

[18] J.-B. Huang, S. Tung, C. M. Ho, C. Liu, and Y. C. Tai, "Improved micro thermal shear-stress sensor," IEEE Trans. Instrum. Meas., vol. 45, no. 2, pp. 570-574, 1996.

[19] F. Jiang, Y. C. Tai, K. Walsh, T. Tsao, G. B. Lee, and C. M. Ho, “A flexible MEMS technology and its first application to shear stress sensor skin," in Proc. MEMS, Nagoya, Japan, 1997, pp. 465-470.

[20] M. A. Schmidt, R. T. Howe, S. D. Senturia, and J. H. Haritonidis, "Design and calibration of a microfabricated floating-element shear-stress sensor," IEEE Trans. Electron Devices, vol. 35, pp. 750-757, 1988.

[21] S. T. Cho, K. Najafi, C. e. Lowman, and K. D. Wise, "An ultrasensitive silicon pressure-based microflow sensor," IEEE Trans. Electron Devices, vol. 49, pp. 825-835, 1992

[22] T. Sato, H. Okajima, Y. Kashiwase, R. Motegi, and H. Nakajima, "Shear horizontal acoustic plate mode viscosity sensor," Jpn. J. Appl. Phys., vol. 32, pp. 2392-2395, 1993.

[23] J. W. Grate, S. J. Martin, and R. M. White, "Acoustic wave microsensors I," Anal. Chem., vol. 65, no. 21, pp. 940A-948A, 1993.

[24] _ , "Acoustic wave microsensors II," Anal. Chem., vol. 65, no. 22, pp. 987A-996A, 1993.

[25] B. A. Martin, S. W. Wenzel, and R. M. White, "Viscosity and density sensing with ultrasonic plate waves," Sens. Actuators A, Phys., vol. 21-23, pp. 704-708, 1990.

[26] C. Zhang, J. J. Caron, and J. F. Vetelino, "The Bleustein-Gulyaev wave for liquid sensing applications," Sens. Actuators B, Chem., vol. 76, pp. $64-68,2001$

[27] F. Herrmann, D. Hahn, and S. Büttgenbach, "Separate determination of liquid density and viscosity with sagitally corrugated love-mode sensors," Sens. Actuators A, Phys., vol. 78, pp. 99-107, 1999.

[28] P. Galambos and F. Forster, "An optical micro-fluidic viscometer," in Proc. ASME Int. Mech. Eng. Conference and Exposition, vol. 66, Anaheim, USA, 1998, pp. 187-191.

[29] F. K. Forster, P. C. Galambos, B. H. Weigl, and M. R. Holl, "Method for Determining Concentration of a Laminar Sample Stream," U.S. Patent 6134950, 2000.

[30] M. A. Haney, "The differential viscometer I. A new approach to the measurement of specific viscosities of polymer solutions," J. Appl. Polymer Sci., vol. 30, pp. 3023-3036, 1985.

[31] - "The differential viscometer II. On-line viscosity detector for size-exclusion chromatography," J. Appl. Polymer Sci., vol. 30, pp. 3037-3049, 1985 .

[32] — "United States Patent: Capillary Bridge Viscometer," U.S. Patent 4463598,1984

[33] E. Chmela, M. T. Blom, F. H. van der Heyden, A. van den Berg, J. G. E. Gardeniers, and R. Tijssen, "Device for Measuring the Viscosity of a Fluid," European Patent application, no. WO2001NL00365, May 14, 2001.

[34] G. K. Batchelor, An Introduction to Fluid Mechanics. Cambridge, U.K.: Cambridge University Press, 1967.

[35] C. van Rijn, M. van der Wekken, W. Nijdam, and M. Elwenspoek, "Deflection and maximum load of microfiltration membrane sieves made with silicon micromachining," J. Microelectromech. Syst., vol. 6, pp. 48-54, 1997.

[36] F. H. J. van der Heyden, M. T. Blom, J. G. E. Gardeniers, E. Chmela, M. Elwenspoek, R. Tijssen, and A. van den Berg, "A low hydraulic capacitance pressure sensor for integration with a microviscosity detector," Sens. Actuators B, Chem., vol. 92, no. 1-2, pp. 102-109, 2003.

[37] H. Jansen, M. de Boer, H. Wensink, B. Kloeck, and M. Elwenspoek, "The black silicon method. VIII. A study of the performance of etching silicon using SF6/O2-based chemistry with cryogenical wafer cooling and a high density ICP source," Microelectron. J., vol. 32, no. 9, pp. 769-777, 2001.

[38] M. de Boer, H. Gardeniers, H. Jansen, E. Smulders, M. J. Gilde, G. Roelofs, J. N. Sasserath, and M. Elwenspoek, "Guidelines for etching silicon MEMS structures using fluorine high density plasmas at cryogenic temperatures," J. Microelectromech. Syst., vol. 11, pp. 385-401, 2002.

[39] H. Wensink, J. W. Berenschot, H. V. Jansen, and M. C. Elwenspoek, "High resolution powder blast micromachining," in Proc. MEMS, Miyazaki, Japan, 2000, pp. 769-774.

[40] H. Wensink, H. V. Jansen, J. W. Berenschot, and M. C. Elwenspoek, "Materials and process technology-Mask materials for powder blasting," J. Micromech. Microeng., vol. 10, pp. 175-180, 2000.

[41] P. J. Slikkerveer, P. C. P. Bouten, and F. C. M. de Haas, "High quality mechanical etching of brittle materials by powder blasting," Sens. Actuators A, Phys., vol. 85, pp. 296-303, 2000.

[42] D. S. Viswanath and G. Natarajan, Data Book on the Viscosity of Liquids. New York: Hemisphere Pub. Corp, 1989.

[43] L. Hao and D. G. Leaist, "Binary mutual diffusion coefficients for aqueous alcohols, methanol to 1-heptanol," J. Chem. Eng. Data, vol 41, pp. 210-213, 1996.

[44] D. R. Wheeler and R. Rowley, "Shear viscosity of polar liquid mixtures via nonequilibrium dynamics: Water, methanol and acetone," Mole. Phys., vol. 94, no. 3, pp. 555-564, 1998.

[45] (2002) SPI Silicon Nitride Membrane Window Grids for TEM Structure Probe Inc. [Online]. Available: http://www.2spi.com/catalog/ instruments/silicon-nitride.html

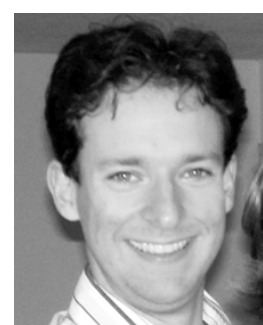

Marko T. Blom was born on November 23, 1974 in Amersfoort, The Netherlands. He received the M.Sc. degree in applied physics from the University of Twente, The Netherlands, in 1998. Also in 1998 , he started working toward the Ph.D. degree at the MESA-Institute of the University of Twente within the Transducers Technology group led by Prof. M. Elwenspoek and within the $\mu$-TAS orientation led by Prof. A. van den Berg. In 2002, he received the $\mathrm{Ph} . \mathrm{D}$. degree for the development of a micromachined integrated analytical system for polymer

characterization

Currently, he is employed by Micronit Microfluidics BV, The Netherlands, as Head of the R\&D Department. 


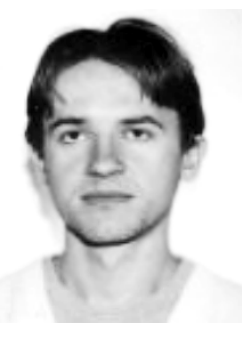

Emil Chmela was born in Prague, Czech Republic, on January 28, 1975. He received the B.S. degree in chemistry at Charles University, Prague, in 1996 and the M.S. degree in physical chemistry from the same in 1998, where he worked on development of capillary electrochromatography in solutions of linear charged polymers. In 2002, he received the $\mathrm{Ph} . \mathrm{D}$. degree from the University of Amsterdam, Department of Chemical Engineering, where he developed a micromachined integrated analytical system for polymer characterization.

Currently, he is working in the Leiden/Amsterdam Center for Drug Research.

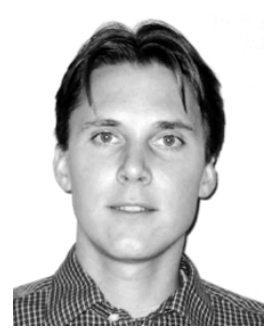

Frank H. J. van der Heyden was born on July 20, 1976 in Boxmeer, The Netherlands. He received the M.Sc. degree in applied physics from the University of Twente, Enschede, The Netherlands, in 2000. He is currently working toward the Ph.D. degree at the Technical University of Delft, The Netherlands, in the Molecular Biophysics group led by Prof. C. Dekker.

His main research interests are the detection and manipulation of biomolecules in nanofluidic channels.

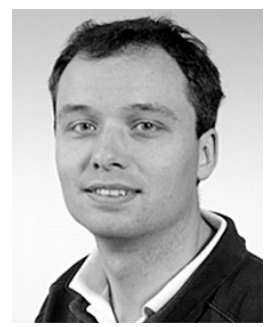

R. Edwin Oosterbroek was born in 1970, Borne, The Netherlands. He received the M.Sc. degree in mechanical engineering from the University of Twente, Enschede, The Netherlands, in 1994.

During his the time of his graduation, he joined the Structures and Materials department of the Dutch National Aerospace Laboratory, NLR. In 1994, he explored the world of microsystem technology at the MESA+ Research Institute, Electrical Engineering department, where he was involved in the micro-pump project. In 1995, he started his Ph.D. project at the same Transducer Technology Laboratory, where he studied modeling, design and fabrication aspects of microfluidics components and systems. Currently, he is working as a Postdoctoral Researcher on microchemical systems design.

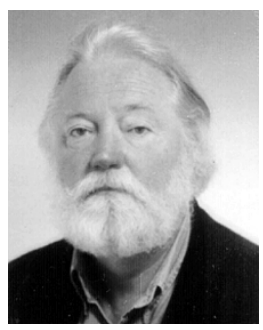

Robert Tijssen was born on June 6, 1944 in Appelbeck, Germany. He received the Ph.D. degree in analytical chemistry at the Technical University Delft (TUD), The Netherlands, in 1979.

His industrial occupation started in 1975 at the Koninklijke Shell Laboratorium Amsterdam (KSLA, presently SRTCA) as a Research Chemist/Physicist and later Workgroupleader in the Analytical Group (AG), section Physical Separations and Organic Chemical Analysis. His current profession is (part-time) Professor in Analytical Chemistry, with a specialization in Separation of Macromolecules, at the UvA (NL) since 1993. Of the other professional duties, a number of Editorial Board memberships and his occupations as Secretary (since 1990) and Chairman (since 1994) of the Workgroup Separation Methods of the Royal Dutch Chemical Society (KNCV) can be mentioned. In this position, twice a year he organizes a one-day (Springand an Autumn) Symposium on new developments in separation science.

Dr. Tijssen was awarded one of the two first Silver Jubilee Medals, founded by the Chromatography Discussion Group, in September 1982, and in 1990, he was invited as a staff-lecturer at the NATO-Advanced Study Institute: "Theoretical Advancement in Chromatography and Related Separation Techniques," Ferrara, Italy.

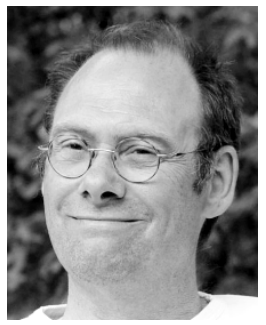

Universität Berlin.

In the same year, he moved to Nijmegen, The Netherlands, to study crystal growth of organic crystals in the group of Prof. Bennema of the University of Nijmegen. In 1987 Miko went to the University of Twente, to take charge of the micromechanics group of the Sensors and Actuators lab, now called the MESA Research Institute. Since then his research focused on microelectromechanical systems, such as design and modeling of micropumps, resonant sensors and electrostatic microactuators for microrobots. Fabrication techniques such as the physical chemistry of wet chemical anisotropic etching, reactive ion etching, wafer bonding, chemical-mechanical polishing and the materials science of various thin films have his special attention. Since 1996, he has been employed as a full professor at the Transducer Technology group at the Faculty of Electrical engineering of the University of Twente.

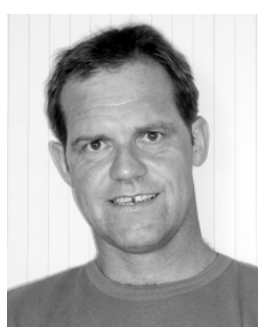

Albert van den Berg received the Masters degree in applied physics from the University of Twente, The Netherlands, in 1983. In 1988, he received the Ph.D. degree from the same university on the topic of chemically modified ISFETs.

From 1988 to 1990, he was with the Swiss Center for Microelectronics and Microtechnology (CSEM) in Neuchâtel, Switzerland, Project Manager in the chemical sensor department. From 1990 to 1993, he did research on miniaturized chemical sensors and sensor systems at the IMT, University of Neuchâtel, Switzerland. From 1993 to 1999 , he was Research Director Micro Total Analysis Systems ( $\mu$-TAS at MESA, University of Twente, a topic that was extended to Miniaturized Chemical Systems (MiCS) in 1999. In 1998, he was appointed as part-time professor "Micro and Nanofluidics", and later in 2000 as full professor on Miniaturized Systems for (Bio)Chemical Analysis in the faculty of Electrical Engineering. His current research interests focus on theory, technologies, new devices and applications of micro- and nanofluidics for miniaturized (bio)chemical synthesis and analysis systems, with a special interest for single-cell based systems.

Dr. van den Berg is member of the $\mu$-TAS, Transducers, and Nanotech steering committees, editor of the section $\mu$-TAS of Sensors and Actuators $B$, Chemical and member of the advisory board of the Lab-on-Chip journal. He was Chairman of the $\mu$-TAS conference in 1994 and 2000, Chairman of the 2003 GRC on Microfluidics, and Chairman of the international Nanotech 2003 conference. In 2002, he received the Simon Stevin Master award from the Dutch Technical Science foundation. 